\title{
EL PARLAMENTO EN LOS TIEMPOS DEL CORONAVIRUS: EL RECURSO A LA DIPUTACIÓN PERMANENTE
}

\section{The Spanish Parliament in the time of coronavirus: the recourse to the Permanent Deputation}

\author{
MANUEL CARRASCO DURÁN \\ Universidad de Sevilla \\ manuelcarrascoduran1@gmail.com
}

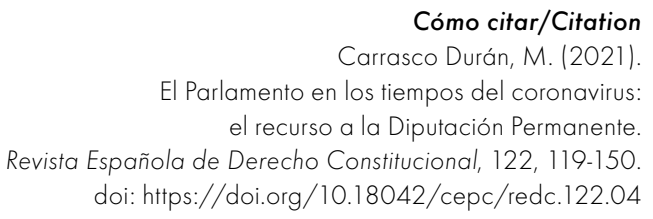

\section{Resumen}

El presente trabajo describe los cambios que ha experimentado la actividad de los Parlamentos durante la pandemia de la covid-19, en lo relativo tanto a las Cortes como a las comunidades autónomas. Se examina, con especial detalle, la convocatoria de la Diputación Permanente en algunos Parlamentos autonómicos, como instrumento para mantener la presencia del Parlamento en la vida pública, especialmente para asegurar el control del Gobierno en la fase más aguda de la pandemia. Se considera que las dificultades originadas por la pandemia revelaron una laguna en los reglamentos parlamentarios y que la convocatoria de la Diputación Permanente, en tales circunstancias, puede apoyarse en el principio general de continuidad de la institución parlamentaria y en la aplicación, por analogía, de las normas que prevén la Diputación Permanente como solución de continuidad en los lapsos entre períodos de sesiones y entre legislaturas. 


\title{
Palabras clave
}

Parlamento; Diputación Permanente; covid-19; reglamento parlamentario; lagunas normativas, analogía.

\begin{abstract}
This article is about the changes that Spanish Parliament's work has undergone during the COVID-19 pandemic, both at national and regional levels. The convening of the Permanent Deputation in the assemblies of some autonomous regions in that period is studied in special detail, as an instrument to maintain the public presence of the legislature in the most acute phase of the said pandemic by ensuring the parliamentary checking of the work of regional governments. It is understood that the difficulties caused by the COVID-19 pandemic revealed a loophole in the Parliaments' Rules of Procedure. In this framework, the activity of the Permanent Deputation finds its legal basis in the general principle that ensures the continuity of the legislature and the application by analogy of the provisions that envisage the convening of the said body during parliamentary recess or when the legislature is not in session.
\end{abstract}

\section{Keywords}

Parliament; legislature; Permanent Deputation; COVID-19; Parliaments' Rules of Procedure; legal loopholes; analogy. 
I. EL PARLAMENTO, EN LA FASE AGUDA DE LA CRISIS SANITARIA DE LA COVID-19. II. LA HABILITACIÓN DE LA DIPUTACIÓN PERMANENTE DURANTE LA FASE MÁS AGUDA DE LA COVID-19. PRÁCTICA Y FUNDAMENTACIÓN JURÍDICA. III. CUESTIONES ESPECÍFICAS: 1. La discusión sobre la existencia de una laguna en los reglamentos parlamentarios. 2. El derecho a ejercer las funciones parlamentarias de los diputados que no sean parte de la Diputación Permanente (artículo 23.2 CE). 3. Las alternativas. 4. La convocatoria de la Diputación Permanente y el artículo 116.5 de la Constitución. 5. Las funciones asumidas por las Diputaciones Permanentes en el marco de la crisis sanitaria. IV. APRECIACIONES FINALES Y CONCLUSIONES. BIBLIOGRAFÍA.

\section{EL PARLAMENTO, EN LA FASE AGUDA DE LA CRISIS SANITARIA DE LA COVID-19}

Es conocido que la crisis sanitaria derivada de la covid-19 ha supuesto una grave interferencia en la actividad de casi todos los Parlamentos de los Estados democráticos. La necesidad de salvaguardar la salud de los diputados y del personal al servicio del Parlamento provocó en la fase más aguda de la primera ola de la pandemia que, en muchos lugares, la actividad parlamentaria se adaptara para evitar el riesgo de contagio. La dificultad de desplazarse de los diputados debida a las restricciones a la circulación impuestas durante el período de mayor incidencia del coronavirus fue un factor adicional de entorpecimiento de la actividad parlamentaria. Finalmente, los parlamentarios, como representantes populares, y el propio Parlamento, como institución, se vieron en la necesidad de dar ejemplo ante la población en la fase más aguda de la epidemia, en la que se multiplicaban los avisos de las autoridades para limitar al máximo la circulación y observar lo que se ha dado en llamar medidas de «distanciamiento social».

Los distintos Parlamentos afrontaron el reto que supuso la emergencia sanitaria de la covid-19 con decisiones de diferente sentido. En unos casos, se optó por suspender totalmente la actividad parlamentaria en fechas variables entre mitad de marzo y final de abril, como sucedió significativamente en el Reino Unido, donde ambas Cámaras, mediante decisión de 25 de marzo de 2020, resolvieron adelantar una semana el 
receso de Pascua ${ }^{1}$, pero también en países como Letonia, los Países Bajos, Suiza, Nueva Zelanda y, ya en la segunda oleada del coronavirus, Australia. En otros casos, se acordó adaptar o limitar la actividad parlamentaria con el fin de hacerla compatible con las medidas de precaución recomendadas para evitar contagios. Entre las medidas que se aplicaron a tal fin señalaremos, sin otra pretensión que la de poner algunos ejemplos significativos, la reducción del quórum de asistencia (Alemania) o del quórum de votación (Portugal); la habilitación de reuniones y votaciones por medios telemáticos (Alemania) ${ }^{2}$; la presencia reducida de parlamentarios; la limitación de la actividad a iniciativas sobre materias que requerían una discusión urgente, como las relacionadas con el presupuesto y la propia covid-19 (Canadá, Austria, Francia); la limitación o la supresión temporal de las sesiones de las comisiones (Finlandia, Italia, Letonia y Portugal) y la celebración de sesiones de comisiones en salas diferentes de las habituales o en el salón del Pleno (Bélgica, Dinamarca), o bien la celebración de sesiones fuera de la sede de las Cámaras (Suiza) ${ }^{3}$.

En España, se registró la misma diversidad en las decisiones que las distintas Cámaras, tanto a escala estatal como a escala autonómica, adoptaron para afrontar el reto que ha supuesto la pandemia de la covid-19. Fue regla general que las Cámaras acordaran la suspensión de los plazos de las iniciativas parlamentarias, lo que comportó la suspensión de la actividad parlamentaria. A partir de ahí, en algunos casos se llevó a efecto una suspensión total de la actividad parlamentaria, salvo reuniones de la Mesa y de la Junta de Portavoces por vía telemática, como en la Asamblea de Madrid, la Asamblea de Murcia, el Parlamento de La Rioja y las Cortes de Castilla-La

1 El 18 de marzo se había solicitado ya que solamente estuvieran presentes en las sesiones los diputados que fueran a intervenir en relación con cada iniciativa (Guerrero Vázquez, 2020: 205).

2 Para el caso de Alemania, véase Kölling (2020: 193).

3 Sobrepasaría con mucho la extensión apropiada para un trabajo como este la descripción en detalle de las decisiones que se han adoptado en cada Cámara para tratar las dificultades surgidas durante la crisis sanitaria de la covid-19. Las referencias que se hacen en el texto, aunque sucintas, son suficientes, entendemos, para ofrecer un esbozo de las adaptaciones que ha sufrido la actividad parlamentaria en el contexto de los Estados con sistemas democráticos. Para un detalle país por país, puede consultarse la página web de la Unión Interparlamentaria, disponible en https://bit.ly/3ikyHQQ, y el dosier de información sobre la covid-19 de la Asamblea de la República portuguesa, en https://bit.ly/3gN5614, y, para un análisis por temas, la información de la Biblioteca de la Cámara de los Comunes, en https://bit.ly/2RtYv1N, y de la Hansard Society, en https://bit.ly/35IPgyf. 
Mancha. En estas Cámaras, normalmente, se reanudó la actividad de las comisiones a mitad del mes de abril ${ }^{4}$, acudiendo a instrumentos como las sesiones telemáticas, o bien la presencia reducida y el voto ponderado.

En la mayoría de los casos, por el contrario, se optó por mantener una actividad parlamentaria adaptada, es decir, reducida al control de la actuación del Ejecutivo mediante comparecencias de los miembros de los respectivos Gobiernos competentes en las materias más afectadas por los retos sanitarios y sociales derivados de la pandemia, y, eventualmente, a la convalidación de decretos leyes. Dentro de los Parlamentos que escogieron esta solución, el grupo más numeroso optó por habilitar la convocatoria de la Diputación Permanente, como solución de continuidad de la actividad parlamentaria indispensable. Esta vía fue la elegida por el Parlamento de Andalucía, las Cortes Valencianas, las Cortes de Castilla y León, la Asamblea de Extremadura, el Parlamento de las Islas Baleares y el Parlamento de Canarias. A estos hay que añadir el Parlamento Vasco y el Parlamento de Galicia, que habían convocado a sus respectivas Diputaciones Permanentes por haberse terminado la legislatura debido a la convocatoria de elecciones, pero que, como veremos, extendieron las funciones de sus Diputaciones Permanentes en la fase aguda de la pandemia más allá de lo habitual hasta abarcar comparecencias de miembros del Consejo de Gobierno e, incluso, preguntas y el debate y votación de proposiciones no de ley. Como caso singular, en las Cortes de Aragón se acordó la celebración de sesiones plenarias, pero con la composición de la Diputación Permanente.

Finalmente, algunos Parlamentos pusieron en práctica soluciones singulares. En las Cortes, se optó, sustancialmente, por celebrar, con presencia drásticamente reducida de parlamentarios, determinadas sesiones que resultaban necesarias, por derivarse dicha prescripción de la propia Constitución, como ocurrió, en el Congreso de los Diputados, en relación con el debate y el acuerdo sobre la prórroga del estado de alarma y, en el Senado, con la singular sesión del 17 de marzo de 2020 acerca de la autorización para la ratificación de un convenio internacional, para todo lo cual, además, se extendió sobre lo previsto en la letra de sus reglamentos la aplicación del voto telemático 5 . El

4 En las Cortes de Castilla-La Mancha hubo una sesión de la Comisión de Sanidad el 26 de marzo, para comparecencia del consejero por videoconferencia. No hubo más actividad estrictamente parlamentaria hasta la sesión del Pleno de 2 de mayo, con la comparecencia del presidente de la comunidad. La actividad de las comisiones se reanudó, de hecho, el 14 de mayo.

5 En el Congreso de los Diputados, la presidenta anunció la suspensión de la actividad parlamentaria el 12 de marzo de 2020 durante quince días, si bien se mantuvieron 
Parlamento de Cataluña mantuvo las sesiones de comisiones de forma no presencial, pero no celebró un Pleno hasta el 24 de abril con presencia reducida y una combinación de voto delegado y telemático (Ridao Martín, 2020: 82). El Parlamento de Navarra convocó sesiones de su Comisión de Régimen Foral, para la comparecencia de la presidenta del Gobierno, y del Pleno, para el debate de proyectos de ley relativos a medidas para tratar la emergencia de la covid-19 y la convalidación de decretos leyes, con presencia reducida a un representante de cada grupo, y, en el caso del Pleno, con delegación de voto. El Parlamento de Cantabria creó una Comisión especial no permanente para el estudio y seguimiento de la situación derivada de la crisis del coronavirus, para sustanciar comparecencias ${ }^{6}$. En la Junta General del Principado de Asturias se creó un grupo de trabajo como alternativa para las comparecencias de miembros del Consejo de Gobierno en sesiones de control (Fernández Gutiérrez, 2020: 56).

En fin, los Parlamentos, en la fase más aguda de la pandemia, se han visto ante el dilema de suspender su actividad o bien articular vías de continuidad de la actividad parlamentaria que se escapan de las prácticas hasta entonces aceptadas en el ámbito parlamentario y académico.

las reuniones de la Mesa y la Junta de Portavoces (en su mayoría, por vía telemática). El 18 de marzo compareció ante el Pleno el presidente del Gobierno; el 25 de marzo se celebró sesión plenaria para acordar la prórroga del estado de alarma y la convalidación de cinco decretos leyes, con presencia reducida a 43 miembros y habilitación del voto telemático. El 2 de abril compareció ante la Comisión correspondiente el ministro de Sanidad. El 7 de abril, la Mesa acordó retomar las sesiones de control del Gobierno, lo que marca el inicio de la desescalada en la Cámara. El 9 de abril, el Pleno se reunió para acordar la segunda prórroga del estado de alarma y la convalidación de tres decretos leyes. No es hasta el 15 de abril cuando se celebra la primera sesión plenaria de control al Gobierno. En el Senado, la Mesa extendió el 12 de marzo el voto telemático a todos los senadores. El 17 de marzo tuvo lugar una sui generis sesión relativa a un convenio internacional con el voto telemático de 259 senadores y la presencia de solamente cinco, de ellos cuatro integrantes de la Mesa y un senador que había tenido problemas al emitir su voto telemático. El mismo 17 de marzo, la Mesa acordó suspender las sesiones del Pleno y las comisiones mientras durase el estado de alarma. Mediante acuerdo de la Mesa de 14 de abril se inició la vuelta a la actividad parlamentaria, de forma que la primera sesión plenaria de control al Gobierno se celebró el 21 de abril con presencia reducida de senadores a un máximo del 10 \% de cada grupo parlamentario (García-Escudero Márquez, 2020: 20-24).

6 Además, celebró el 6 de abril una sesión plenaria con presencia reducida a los portavoces de los grupos, el presidente de la Cámara y dos miembros de la Mesa, para celebrar una comparecencia del presidente de la comunidad y del consejero de Sanidad. 
De hecho, otra nota común a los Parlamentos que optaron por mantener en cierto grado su actividad ha sido la práctica de orillar la literalidad de las previsiones de sus reglamentos como recurso imprescindible para aplicar soluciones que pudieran preservar un cierto grado de actividad parlamentaria en condiciones compatibles con las medidas necesarias para evitar los riesgos derivados de la pandemia y las trabas a la movilidad emanadas de las medidas de confinamiento. Las soluciones aplicadas se instrumentaron, mayoritariamente, a través de acuerdos de las Mesas ${ }^{7}$, con el consenso de todos los grupos, $\mathrm{y}$, ocasionalmente, mediante resolución de la respectiva presidencia ${ }^{8}$. Ciertamente, los acuerdos de las Mesas han puesto de relieve la consabida ductilidad del derecho parlamentario, nemine contradicente, pero también los riesgos de este instrumento, puesto que dicho consenso, en algunos Parlamentos, se fue rompiendo conforme evolucionaba la pandemia, lo que generó algunos conflictos en los que se mezclaban ingredientes políticos y jurídicos?

7 Sobre la virtualidad de los acuerdos de las Mesas como fuente del derecho parlamentario puede verse Astarloa Huarte-Mendicoa (2016: 43-44).

8 Para la consulta de los acuerdos y normas adoptados en los Parlamentos de las comunidades autónomas para adaptar su actividad a causa de la pandemia de la covid-19, véase el dosier Parlamentos y COVID-19 de las Cortes Valencianas, disponible en https://bit.ly/3w48H0e (última consulta, 11 de enero de 2021). Asimismo, constituyen lectura imprescindible los trabajos recopilados en Tudela Aranda (2020), y el de García-Escudero Márquez (2020: 271-308).

9 El caso más sobresaliente ha sido la polémica generada en el Parlamento de Andalucía a raíz de la convalidación del Decreto Ley 2/2020, de 9 de marzo, de mejora y simplificación de la regulación para el fomento de la actividad productiva de Andalucía, llevada a cabo en la sesión de la Diputación Permanente del 2 de abril de 2020, que ha motivado la presentación de sendos recursos de amparo por un diputado del Grupo Socialista y por los diputados del Grupo Adelante Andalucía en el Parlamento andaluz y de dos recursos de inconstitucionalidad por parte de senadores pertenecientes al Grupo Socialista en el Senado y de diputados del Grupo Parlamentario Confederal de Unidas Podemos-En Comú Podem-Galicia Común y otros grupos, si bien este último ha sido inadmitido por extemporáneo mediante el ATC 174/2020, de 15 de diciembre. Hay que recalcar, no obstante, en relación con los recursos de amparo, que el acuerdo de la Mesa mediante el que se autorizaba a la presidenta del Parlamento de Andalucía la adopción de una resolución para la convocatoria de la Diputación Permanente fue adoptado por unanimidad de los grupos parlamentarios, incluyendo aquellos a los que pertenecen los diputados recurrentes, que la Resolución de la Presidenta del Parlamento de Andalucía sobre la convocatoria de la Diputación Permanente durante la vigencia del estado de alarma fue decidida también contando con el parecer unánime de los miembros de la Mesa y de la Junta de Portavoces, y que en las reuniones de la Diputación Permanente celebradas se acordó la convalidación 
Para acabar con el presente apartado introductorio, debemos aclarar que las medidas de suspensión o continuidad de la actividad parlamentaria examinadas previamente se refieren a la fase inicial de la pandemia, en la que el riesgo para la salud pública y los problemas de movilidad de los diputados y el personal de las Cámaras se hicieron sentir de forma más aguda, esto es, entre mitad de marzo y final de abril de 2020. Las medidas adoptadas por los Parlamentos para hacer frente a las dificultades generadas por la covid-19 han tenido un carácter dinámico, de manera que han ido cambiando conforme evolucionaba la crisis sanitaria. Con el paso del tiempo, las medidas enunciadas anteriormente, incluyendo la habilitación de la Diputación Permanente como solución de continuidad, fueron abandonándose para dar lugar a una práctica caracterizada, en líneas generales, y con independencia de las singularidades de cada Parlamento, por admitir la reunión de la Mesa y la Junta de Portavoces en modalidad telemática, habilitar la celebración de sesiones de Pleno y de las comisiones con presencia reducida de parlamentarios y generalizar el ejercicio del voto telemático o de la delegación de voto para los diputados no asistentes presencialmente, algo que, en ocasiones, se ha aplicado también en las comisiones.

En las siguientes páginas, nos centraremos en explicar la fundamentación que, a nuestro juicio, podría dar soporte jurídico a la opción de solventar las dificultades generadas para el desarrollo de la actividad parlamentaria en la fase más aguda de la pandemia mediante la convocatoria de la Diputación Permanente, pero, más allá del objetivo anterior, pensamos que el trabajo puede resultar útil también para proporcionar criterios que expliquen desde la interpretación jurídica las demás alternativas seguidas por los Parlamentos en dicho período ${ }^{10}$.

de otros siete decretos leyes sin que se registrara el voto contrario de ningún diputado. Además, el presidente del Gobierno promovió un recurso de inconstitucionalidad frente a determinados artículos de la citada norma en el que se alegaba la vulneración de competencias del Estado. Esta controversia ha concluido mediante acuerdo alcanzado en la respectiva comisión bilateral.

10 La redacción del trabajo se concluyó antes de que el Tribunal Constitucional se pronunciara sobre la admisión a trámite de los recursos citados en la nota anterior y, por lo tanto, sin conocer los argumentos que sostenían dichos recursos. 


\section{LA HABILITACIÓN DE LA DIPUTACIÓN PERMANENTE DURANTE LA FASE MÁS AGUDA DE LA COVID-19. PRÁCTICA Y FUNDAMENTACIÓN JURÍDICA}

Como hemos mencionado anteriormente, la habilitación de la Diputación Permanente fue la solución adoptada por los Parlamentos de Andalucía, Canarias, Castilla y León, Comunidad Valenciana, Extremadura e Islas Baleares para mantener la actividad parlamentaria en la fase más aguda de la pandemia de la covid-19. Además, actuó la Diputación Permanente en los Parlamentos de Galicia y el País Vasco, donde se había convocado con ocasión de la disolución de la respectiva Cámara y la correlativa convocatoria de elecciones.

El grado de actividad de la Diputación Permanente fue distinto en cada Parlamento. Así, en las Cortes de Castilla y León solamente tuvo lugar una sesión de la Diputación Permanente, el día 17 de marzo de 2020, para la comparecencia a petición propia del presidente de la Junta de Castilla y León, sobre evolución y medidas adoptadas con motivo de la covid-19. La siguiente actividad parlamentaria que se registró en dicho Parlamento fue la sesión del Pleno que tuvo lugar el 24 de abril, cuyo orden del día fue una nueva comparecencia del presidente de la comunidad autónoma y la convalidación un decreto ley. El caso es interesante, ya que, al abandono de la solución de la Diputación Permanente, siguieron cinco semanas sin actividad propiamente parlamentaria, salvo las reuniones de la Mesa y la Junta de Portavoces. Esta última es, precisamente, la situación que se pretendió evitar en otros Parlamentos dando mayor actividad a la Diputación Permanente.

En el Parlamento de las Islas Baleares hubo dos sesiones de este órgano, la del día 23 de marzo, en la que se sustanció una comparecencia a petición de la presidenta del Consejo de Gobierno, y la del 7 de abril, en la que se llevó a efecto la convalidación de tres decretos leyes.

En la Asamblea de Extremadura, entre el 19 de marzo y el 23 de abril, hubo tres sesiones de la Diputación Permanente, en las que se sustanciaron una comparecencia del vicepresidente segundo y consejero de Sanidad y Servicios Sociales, la convalidación de tres decretos leyes y la comparecencia del presidente de la Junta de Extremadura ${ }^{11}$.

En el Parlamento de Andalucía, la Diputación Permanente celebró cuatro sesiones entre el 25 de marzo y el 24 de abril, al ritmo de una por semana salvo en el período de Semana Santa ${ }^{12}$, en el curso de las cuales hubo

11 Sesiones de 19 de marzo, 20 de abril y 23 de abril de 2020 .

12 Sesiones de los días 25 de marzo y 2, 16 y 24 de abril de 2020. 
doce comparecencias de titulares de consejerías, entre las que destacan las cuatro del consejero de Salud y Familias, más la comparecencia del presidente de la Junta de Andalucía, que se produjo en la última de dichas sesiones. Además, se convalidaron ocho decretos leyes.

La Diputación Permanente de las Cortes Valencianas celebró cinco sesiones entre el 22 de abril y el 8 de mayo de $2020^{13}$, en el curso de las cuales comparecieron el presidente del Consejo de Gobierno, la vicepresidenta y varios consejeros, se convalidaron cuatro decretos leyes y se aprobó la creación de la Comisión de Estudios para la reconstrucción social, económica y sanitaria como consecuencia de la crisis de la covid-19.

El Parlamento de Canarias celebró, finalmente, ocho sesiones de su Diputación Permanente entre los días 8 de abril y 5 de mayo de $2020^{14}$, a un ritmo de dos por semana, en el curso de las cuales comparecieron, conforme a un calendario aprobado en la sesión del 8 de abril, el presidente de Canarias, el vicepresidente y los titulares de las respectivas consejerías, y, además, se convalidaron dos decretos leyes. En la sesión del 8 de abril, junto con lo anterior, se aprobó una declaración institucional y la resolución de la Mesa del Parlamento por la que se autorizaba la celebración de reuniones de la Diputación Permanente a través de sistemas telemáticos y la delegación de voto de sus integrantes, a consecuencia de la pandemia de coronavirus. De esta forma, se autorizó a la Diputación Permanente a asumir las competencias que le son propias y las que, de manera excepcional, se le otorgaban en dicha resolución durante el período en el que estuviera vigente el estado de alarma.

Casos particulares son los de Galicia y el País Vasco. El Parlamento de Galicia y el Parlamento Vasco tenían convocada la Diputación Permanente, debido a que habían quedado disueltos el 12 de febrero, a consecuencia de la convocatoria de elecciones en ambas comunidades. Como se sabe, las elecciones, previstas en un principio para el 5 de abril, fueron aplazadas el día 16 de marzo, como consecuencia de la pandemia de la covid-19. En este marco, los servicios jurídicos del Parlamento de Galicia emitieron un informe en el que se afirma, primero, que la Diputación Permanente tiene competencia para tramitar las iniciativas relacionadas con facultades individuales de los diputados pertenecientes a la función de control, como las solicitudes de información y las preguntas, así como las comparecencias y las declaraciones institucionales; segundo, que, aunque el caso es dudoso, sería posible para la Diputación Permanente tramitar iniciativas pertenecientes a la función de impulso de la actividad del Gobierno, tales como interpelaciones, mociones y proposiciones no de ley,

13 Sesiones celebradas los días 22 y 23 de abril de 2020 y 6,7 y 8 de mayo de 2020 .

14 Sesiones de los días 8, 14, 17, 21, 24, 28 y 29 de abril y 5 de mayo de 2020. 
siempre que ello fuera avalado por el consenso de los grupos; tercero, que resultaría contrario a la Constitución atribuir a la Diputación Permanente funciones relativas a la tramitación de iniciativas legislativas (Sarmiento Méndez, 2020: 107-109). En el Parlamento Vasco, los servicios jurídicos emitieron un informe en el que se rechazaban las sesiones telemáticas de la Diputación Permanente, pero, además, interesa destacar que se originó un debate en el que debieron conciliarse las posturas de los grupos parlamentarios de la oposición, que pretendían extender las posibilidades de actuación de la Diputación Permanente ante el aplazamiento de las elecciones, con los límites propios de la actividad de dicho órgano. De hecho, la Declaración Institucional de 18 de marzo de 2020, entre otras cosas, encargaba a la Diputación Permanente velar por «todos los poderes y funciones» de la Cámara, para lo que habría de ejercer «el debido y efectivo control de la actividad del Gobierno Vasco» (Iturbe Mach, 2020: 99-100).

Como resultado de lo anterior, tanto en el Parlamento de Galicia como en el Parlamento Vasco se han celebrado varias sesiones de la Diputación Permanente en las que se han tramitado, en el primero de ellos, comparecencias informativas del presidente de la Junta de Galicia y de consejeros y preguntas, y, en el segundo, comparecencias del lehendakari y de un consejero y proposiciones no de ley.

Entre los demás Parlamentos, interesa dar cuenta del caso de las Cortes de Aragón. En estas, el Pleno acordó el 13 de marzo de 2020 que las sesiones plenarias, en adelante, se celebrarían «adoptando el formato de Diputación Permanente a efectos de presencia y votaciones». Asimismo, se previó que las sesiones de las comisiones se hicieran "en un formato reducido, con la presencia únicamente de un portavoz por Grupo y adopción de acuerdos por voto ponderado». El día 16 de marzo, mediante acuerdo de la Mesa y de la Junta de Portavoces, se ratificó esta particular decisión, sin bien se resolvió restringir la actividad parlamentaria a la "que resulte imprescindible por cuestiones relacionadas estrictamente con el control de la COVID-19 o la gestión del estado de alarma en la Comunidad». Como resultado, no hubo sesiones, ni de Pleno ni de comisiones, entre la segunda quincena de marzo y la primera semana de abril, aunque la Mesa y la Junta de Portavoces siguieron reuniéndose de forma telemática y se produjeron reuniones de una comisión de seguimiento. Las sesiones del Pleno se reanudaron el 15 de abril, con el formato de Diputación Permanente, primero con actividad reducida a iniciativas relacionadas con la gestión por el Gobierno de la pandemia y, a partir del 20 de mayo, extendiendo su actividad a las demás materias. Las comisiones reanudaron el 17 de abril sus sesiones por videoconferencia para asuntos relacionados con la covid-19 y, a partir del 18 de mayo, pasaron a reunirse presencialmente, y abriendo el abanico de materias, en el Salón de plenos. 
Dejando a un lado ahora la problemática específica del Parlamento de Galicia y del Parlamento Vasco, la cuestión reside en determinar cuál es la fundamentación jurídica que, en su caso, permitiría convocar a la Diputación Permanente como solución de continuidad de la actividad parlamentaria en supuestos como el vivido a raíz de la emergencia sanitaria de la covid-19.

A nuestro juicio, para encontrar un razonamiento que avale en tal supuesto la convocatoria de la Diputación Permanente es necesario afirmar que la pandemia de la covid-19, con las dificultades sobrevenidas para seguir normalmente la actividad parlamentaria, ha revelado la existencia de una laguna en los reglamentos de nuestras Cámaras. Los Reglamentos parlamentarios recogen dos supuestos de cese de la actividad por disposición normativa, los existentes entre períodos de sesiones ("vacaciones parlamentarias») y entre legislaturas, una vez expirado el mandato parlamentario o disuelta la Cámara y hasta la constitución de la nueva, pero no regulan supuestos de suspensión fáctica de la actividad parlamentaria por la concurrencia de circunstancias que, de hecho, la trastornen gravemente o la hagan imposible.

Esta laguna normativa debe resolverse utilizando los dos medios que la hermenéutica jurídica admite generalmente a tal fin, que son los principios generales del derecho y la analogía. El principio general del derecho aplicable en estos supuestos es el de continuidad de la institución parlamentaria ${ }^{15}$. En los casos de suspensión de la actividad parlamentaria, la Constitución y los estatutos de autonomía han dispuesto un órgano, la Diputación Permanente, que tiene como finalidad velar por los poderes de las Cámaras cuando no estén reunidas, con lo que se evitan interrupciones en el funcionamiento del Parlamento.

La analogía consiste en aplicar a una determinada situación no tratada por el ordenamiento jurídico la solución ofrecida por aquel para una situación parecida. En este sentido, partiendo de la convocatoria de la Diputación Permanente en los supuestos de cese de la actividad parlamentaria por disposición normativa (fin de los períodos de sesiones y fin de la legislatura), se trataba de aplicar la misma solución al supuesto de cese de la actividad por circunstancias fácticas, de fuerza mayor, que den lugar a imposibilidad o grave dificultad de reunirse de los diputados. El propósito de dichos supuestos, tanto los regulados expresamente como el apreciado por analogía, es el mismo, es decir, asegurar la continuidad de la institución parlamentaria, aun cuando se produzca la suspensión de su actividad ordinaria.

15 Sobre la nota de la continuidad, puede verse Alonso de Antonio (1986: 181-182). Para una síntesis del debate sobre la naturaleza de la Diputación Permanente, véase Caamaño Domínguez (1991: 293-298). 
En el marco de la analogía, la situación creada en fase más aguda de la pandemia de la covid-19 encuentra vínculos con los dos supuestos de convocatoria de la Diputación Permanente aceptados expresamente en nuestro ordenamiento. Se asemejaba a los lapsos entre períodos de sesiones porque se trataba de supuestos de suspensión de la actividad parlamentaria ordinaria sin que las Cámaras estuvieran disueltas, salvo los casos del Parlamento Vasco y el Parlamento de Galicia, pero, al mismo tiempo, conectaba con los períodos entre legislaturas porque las Cámaras se encontraban, de facto, imposibilitadas para reunirse.

En los Parlamentos donde se habilitó la convocatoria de la Diputación Permanente, ello ha venido respaldado por acuerdos de las Mesas adoptados por unanimidad $\mathrm{y}$, ocasionalmente, por resoluciones de la presidencia de la respectiva Cámara ${ }^{16}$. A este respecto, hay que recordar la doctrina del Tribunal Constitucional según la cual dicha facultad presidencial solo es admisible cuando se la utilice "para suplir omisiones [del Reglamento] o para interpretarlo, no para desarrollarlo o especificar sus prescripciones» (SSTC 118/1988, FJ 4, y 119/1990, FJ 5), lo que significa que no pueden infringirlo ni modificarlo, tal como ha precisado el Tribunal Constitucional en sentencias posteriores (SSTC 118/1988, FJ 4, 44/1995, FJ 2, 226/2004, FJ 5, y 227/2004, FJ 5). La doctrina se manifiesta en el mismo sentido (por todos, Morales Arroyo, 1996: 260).

Así, «sólo puede apreciarse la existencia de una laguna jurídica cuando el contenido normativo que se considera en falta puede de alguna manera considerarse implícito en previsiones normativas expresas dotadas de un contenido equivalente» (STC 226/2004, FJ 5). En este sentido, Ezquiaga y Saiz (1987: 19-21) admiten las que denominan resoluciones objetivas, "cuya finalidad es suplir una laguna reglamentaria surgida como consecuencia de un acto normativo o jurisdiccional externo al propio Reglamento", y resoluciones procedimentales, que tendrían como fin "completar o desarrollar por razones de agilidad o eficacia, procedimientos ya contemplados en el Reglamento».

16 En el Parlamento de Andalucía, mediante la combinación de acuerdo de la Mesa y resolución de la Presidencia; en las Cortes de Castilla y León, mediante acuerdo de la Mesa; en el Parlamento de Canarias, mediante resolución de la Mesa; en la Cortes Valencianas, mediante acuerdo de la Mesa y resolución relativa a la ampliación de los supuestos del voto a distancia, y en el Parlamento de las Islas Baleares y en la Asamblea de Extremadura, mediante acuerdo de la Mesa. En el caso especial de las Cortes de Aragón, mediante acuerdo de la Mesa y la Junta de Portavoces, junto con una resolución para la regulación del voto no presencial. Para los detalles, véanse los trabajos citados en la nota 8 . 
Sin embargo, la doctrina ha rechazado las lagunas impropias o ideológicas, que consisten en la "ausencia de una solución satisfactoria para el intérprete» (Saiz Arnaiz, 1988: 131).

Más allá de las anteriores construcciones doctrinales, lo cierto es que la derivada de la falta de previsión en los reglamentos de situaciones de fuerza mayor que generen graves dificultades o la imposibilidad de desarrollar la actividad parlamentaria ordinaria es una laguna propia, en sentido clásico. Los tipos de resoluciones identificados por los autores citados anteriormente suponen la introducción de innovaciones en la normativa reglamentaria que se justifican, bien por su carácter de detalle que no altera el diseño general de un procedimiento previamente regulado, o bien por la necesidad de articular un procedimiento para tramitar iniciativas previstas en normas externas al reglamento. En el caso que nos ocupa se trató de algo, incluso, de menor alcance, como es buscar dentro del reglamento la solución jurídica para una situación no regulada en dicha norma. No se trataba, por tanto, de innovar las normas de procedimiento, sino de aplicar normas preestablecidas para una situación novedosa, no abordada por el reglamento ${ }^{17}$.

En este marco, la confluencia del principio general de continuidad de la institución parlamentaria y de la analogía con las situaciones de suspensión de la actividad parlamentaria previstas en los reglamentos parlamentarios proporciona, a priori, el sustrato jurídico necesario para dar legitimidad a las resoluciones de la presidencia de los Parlamentos y los acuerdos de sus Mesas que habilitaron la convocatoria de sus Diputaciones Permanentes durante la fase más aguda de la pandemia de la covid- $19^{18}$.

17 La convocatoria de la Diputación Permanente frente a la situación generada por la covid-19 resulta diferente a los casos resueltos por las SSTC 226/2004 y 227/2004. En estos, partiendo del art. 50 del Reglamento del Parlamento de Galicia, que contemplaba solamente causas de extinción sobrevenida de las comisiones no permanentes por circunstancias de hecho (fin de su objeto y fin de la legislatura), se añadió mediante resolución de la Presidencia un nuevo supuesto de naturaleza diferente, como era la imposibilidad de alcanzar su objeto, que introdujo un elemento voluntarista, puesto que dicha imposibilidad no podía ser sino resultado de la decisión de la mayoría de la Comisión mediante un acuerdo de naturaleza política (Pardo Falcón, 2005).

18 Como opiniones críticas, Nieto Jiménez (2020: 263 y 267) entiende que la habilitación de la Diputación Permanente habría requerido reforma del Reglamento, en el caso concreto del Parlamento de Andalucía. García-Escudero Márquez (2020: 189), sin rechazar de plano la opción de habilitar la convocatoria de la Diputación Permanente, critica que no se pusieran en práctica otras alternativas que, a su juicio, habrían dado lugar al mismo resultado con un menor «retorcimiento» de la normativa. 


\section{CUESTIONES ESPECÍFICAS}

Examinamos a continuación de manera específica algunas cuestiones acerca de la convocatoria de la Diputación Permanente como solución de continuidad de la actividad parlamentaria durante la fase de mayor gravedad de la pandemia de la covid-19.

\section{LA DISCUSIÓN SOBRE LA EXISTENCIA DE UNA LAGUNA EN LOS REGLAMENTOS PARLAMENTARIOS}

Desde una interpretación literal de los Reglamentos parlamentarios, podría defenderse que aquellos han manifestado una voluntad expresa de limitar el funcionamiento de la Diputación Permanente solamente a los lapsos entre períodos de sesiones y entre legislaturas, de lo que se derivaría la necesidad de aplicar la regulación ordinaria en cualesquiera otras circunstancias, incluyendo aquellas que, como la pandemia de la covid-19, pudieran afectar de modo excepcional a la actividad parlamentaria.

En nuestra opinión, sin embargo, lo extraordinario de las circunstancias en la fase más aguda de la pandemia requiere superar la rigidez de una interpretación literal o dogmática del reglamento y hacer una interpretación más cercana a la realidad concreta que se vivió en aquel período y a la necesidad que se experimentó de tomar con inmediatez decisiones que permitieran el desarrollo de la actividad parlamentaria de forma compatible con las precauciones exigidas para evitar el riesgo sanitario y las trabas a los desplazamientos derivadas de las medidas de confinamiento, así como con la necesidad de dar a la ciudadanía ejemplo de cumplimiento de las recomendaciones de las autoridades. En el marco descrito, una interpretación literal no se sostiene, ya que conduciría a pensar que las Cámaras, al aprobar sus reglamentos, han tenido la voluntad de someter a los diputados y a su personal al riesgo de verse afectados por una epidemia altamente contagiosa y cuyos efectos podrían, incluso, poner en peligro su vida, lo cual resulta absurdo e, incluso, contrario a bienes protegidos por la Constitución (arts. 15 y 43 CE), o bien abocaría necesariamente a la suspensión de toda la actividad parlamentaria. Como han reconocido algunos autores, la situación era «radicalmente novedosa» (Tudela Aranda, 2020: 7) y «sin precedentes» (García-Escudero Márquez, 2020: 18) ${ }^{19}$,

19 La situación ha sido bien descrita por García-Escudero Márquez (2020: 272): «Muy especialmente el Congreso de los Diputados, al que corresponden competencias específicas en este estado, pero también el Senado y los Parlamentos de las 
$y$, como hemos visto, los Parlamentos hubieron de aplicar soluciones que revestían una dosis de originalidad para poder mantener un grado, siquiera limitado, de actividad parlamentaria.

Por lo tanto, es más consecuente pensar que, sencillamente, al aprobar los reglamentos no se pensó en la eventualidad de sufrir una pandemia que, de hecho, podía poner en peligro la salud, la integridad y, en supuestos extremos, la vida de los diputados y del personal y que añadía graves dificultades para la movilidad, tanto de los diputados como del personal de las Cámaras.

Dada, en fin, una situación de laguna normativa, resulta indiscutible que no se puede abandonar la situación a la anomia y que debe hallarse una regulación para dicha situación en el propio ordenamiento. La analogía es el instrumento generalmente aceptado en el ordenamiento jurídico para deducir la norma que debe regular una situación no prevista en aquel y las soluciones generadas mediante la aplicación de la analogía se deben entender como integrantes del propio ordenamiento.

\section{EL DERECHO A EJERCER LAS FUNCIONES PARLAMENTARIAS DE LOS DIPUTADOS QUE NO SEAN PARTE DE LA DIPUTACIÓN PERMANENTE (ARTÍCULO 23.2 CE)}

Ante todo, hay que precisar que las limitaciones a las facultades de los parlamentarios durante la pandemia de la covid-19 no proceden directamente de la convocatoria de la Diputación Permanente, sino de los acuerdos por los que se decidía, con unas u otras fórmulas, la suspensión de la actividad parlamentaria ordinaria. Como hemos visto, estos acuerdos se extendieron por todos los Parlamentos del Estado español.

La convocatoria de la Diputación Permanente, en un trasfondo de suspensión de la actividad parlamentaria, tenía la finalidad, precisamente, de permitir, siquiera fuera como excepción, el desarrollo de la actividad parlamentaria en casos de urgencia, que, como hemos visto, la práctica hizo cristalizar en la celebración de comparecencias para el control de la actividad de

Comunidades Autónomas en el ejercicio de su función de control al Gobierno, se han encontrado en la coyuntura de hacer de la necesidad virtud y enfrentarse a unas circunstancias para las que no contaban no ya con previsión reglamentaria, sino con instrumentos o herramientas tecnológicas — piénsese en la posibilidad de celebrar reuniones telemáticas con garantías - que permitieran continuar con su actividad... de otra forma». 
cada Consejo de Gobierno y en la convalidación de decretos leyes. En otros términos, la Diputación Permanente fue el instrumento del que se sirvieron los Parlamentos de determinadas comunidades autónomas para mantener la presencia del Parlamento en la vida política, en un escenario en el que las circunstancias obligaban a limitar severamente la actividad parlamentaria para evitar riesgos sanitarios y dificultades de movilidad y para dar ejemplo a la ciudadanía de seguimiento de las recomendaciones de las autoridades sanitarias que desaconsejaban las reuniones.

A pesar de todo, sería posible preguntarse si ha existido una limitación del derecho al voto de los parlamentarios que no son miembros de la Diputación Permanente.

En general, la duda planteada se resuelve distinguiendo el plano de la limitación del de la delimitación de los derechos. Admitida la existencia de una laguna en los reglamentos parlamentarios y la procedencia de solventarla mediante la activación de la Diputación Permanente, en virtud del principio de continuidad de la institución parlamentaria y de la aplicación de la analogía con respecto a las situaciones para las que está prevista expresamente aquella en los reglamentos, es claro que la práctica debía acomodarse a la regulación que los reglamentos llevan a cabo de los requisitos, condiciones y procedimientos que deben observar los diputados mientras dicho órgano se encuentre reunido, esto es, a la delimitación del derecho al ejercicio de las facultades parlamentarias que hacen los reglamentos para la situación de convocatoria de la Diputación Permanente. No puede olvidarse que, según una acreditada doctrina del Tribunal Constitucional, el derecho fundamental del art. $23.2 \mathrm{de}$ la Constitución es de configuración legal.

Por el contrario, entender que la convocatoria de la Diputación Permanente limita indebidamente el derecho de los diputados a ejercer las funciones parlamentarias, derivado del art. 23.2 de la Constitución, supondría una impugnación general de la Diputación Permanente como solución de continuidad de la institución parlamentaria. En derecho comparado existen otras soluciones, pensadas especialmente para los períodos de disolución de la Cámara por expiración de su mandato o convocatoria anticipada de elecciones, como la reunión del Parlamento en determinadas circunstancias excepcionales, según ocurre en Francia y Bélgica ${ }^{20}$, el sistema de prorogatio, propio de Alemania, tras la reforma constitucional de 1976, Países Bajos e Italia $^{21}$, que, en los períodos entre legislaturas, permite a las Cámaras llevar a

20 Art. 16 de la Constitución francesa.

21 Arts. 39 de la ley fundamental alemana, 64 de la Constitución de Países Bajos y 61 de la Constitución italiana. 
cabo actos de urgencia ineludible, o un sistema mixto, que combina la existencia de una Comisión permanente y la convocatoria obligada de la Asamblea en situaciones extraordinarias, propio de Portugal ${ }^{22}$ (González Ayala, 1987: 78-86; Visiedo Mazón, 2016: 217; Santaolalla López, 2013: 220; Caamaño Domínguez, 1991: 283-291), pero el hecho es que nuestra Constitución y los estatutos de autonomía han optado por confiar la continuidad de la institución parlamentaria en los períodos de cese de su actividad ordinaria a un órgano específico, la Diputación Permanente.

Por otra parte, la composición de las Diputaciones Permanentes, al igual que la de las comisiones (STC 214/1990), debe entenderse como conforme con la Constitución, siempre que estén constituidas con arreglo al principio de proporcionalidad, tomando como base la composición de los grupos parlamentarios en el Pleno, y sin perjuicio de que dicha proporcionalidad, por motivos técnicos, no tenga por qué ser estricta (STC 36/1990, FJ 2). Ciertamente, el Tribunal Constitucional ha optado, como principio general, por afirmar que la relación de representación política vincula al diputado individual con los electores (SSTC 5/1983 y 10/1983), pero tampoco ha sido ajeno a la importancia que los grupos parlamentarios tienen en el funcionamiento del Parlamento actualmente (SSTC 64/2002, FJ 3, y 57/2011, FJ 4). Así, ha admitido que el derecho fundamental de los diputados viene modulado por los reglamentos parlamentarios, a los que compete «fijar y ordenar los derechos y atribuciones propios de los parlamentarios» (SSTC 107/2016, FJ 4.B.a; 108/2016, FJ 4.B.a; 115/2019, FJ 4, y 159/2019, FJ 5 c), ha aceptado la posibilidad de reservar el ejercicio de determinadas funciones a los grupos parlamentarios (STC 159/2019, FJ 12) y ha reconocido la práctica de conformar los órganos parlamentarios sobre la base de la composición de los grupos parlamentarios (SSTC 36/1990, FJ 2, 214/1990, FJ 6, y 141/2007, FJ 4).

\section{LAS ALTERNATIVAS}

Partimos de la base de que, en virtud del principio de autonomía parlamentaria, correspondía a cada Cámara concretar las soluciones que debían aplicarse en su interior para afrontar las dificultades derivadas de la pandemia de la covid-19, conforme a la propia evaluación del riesgo sanitario y de los medios para hacerle frente en cada momento.

De hecho, la práctica ha ido mostrando una pluralidad de alternativas para continuar la actividad parlamentaria en el marco de la pandemia de la

22 Art. 182 de la Constitución portuguesa. 
covid-19, sin que sea posible afirmar apriorísticamente la existencia de una única solución, ni excluir ninguna de las opciones factibles. En otras palabras, como dice el Tribunal Constitucional, «el derecho al "procedimiento debido", indudablemente asociado al reconocido en el artículo 23.2 CE, no debe confundirse con un inexistente "derecho" al procedimiento "preferido"» (STC 110/2019, FJ 2).

Ahora bien, todas las alternativas, y no solo la referida a la Diputación Permanente, plantean retos a la interpretación normativa. Las sesiones con presencia reducida de diputados, además de dar lugar a una imagen artificiosa de «Pleno», topan con las previsiones reglamentarias con respecto al quórum de votación (y, en el caso de las comisiones, también al quórum de constitución) y con la duda sobre si es posible limitar la presencia de diputados en las sesiones de los órganos parlamentarios a los que pertenecen; la delegación de voto y el desarrollo telemático de las sesiones se enfrentan a dificultades derivadas de la jurisprudencia del Tribunal Constitucional (SSTC 19/2019, FJ 4, y 45/2019, FJ 4), a ocasionales problemas técnicos y al problema de concepto que supone aplicar como solución general a los debates soluciones previstas para casos singulares y excepcionales; otras soluciones, como la creación de un grupo de trabajo o la convocatoria de plenos con formato de Diputación Permanente, presentan el inconveniente de utilizar instrumentos de la actividad parlamentaria con un objeto diferente al que tienen previsto en cada reglamento ${ }^{23}$.

Ciertamente, el acuerdo político sobre las concretas soluciones para afrontar la crisis sanitaria debe moverse siempre dentro de los límites de la Constitución, del estatuto de autonomía y del reglamento de la Cámara. Ahora bien, esto es compatible con la necesidad, que se experimentó en la fase más aguda de la pandemia, de superar interpretaciones literales de los reglamentos y aplicar, en su lugar, interpretaciones más ajustadas a la realidad que se estaba viviendo y a la propia finalidad de las normas, de manera que fuera posible mantener un cierto grado de actividad parlamentaria y, al mismo tiempo, evitar los riesgos y las dificultades inherentes a la situación. Todo ello, teniendo en cuenta, además, que la reforma del reglamento parlamentario resultaba un remedio imposible en aquel período ante la necesidad de adoptar decisiones de forma urgente y la dificultad para llevar a cabo el debate inherente a cada modificación de dicha norma entre los actores políticos, en un marco en el que la posibilidad de reunirse estaba severamente reducida por la necesidad de evitar riesgos sanitarios y mantener el confinamiento

23 Sobre el inconveniente de las reformas del reglamento en circunstancias de crisis, García-Escudero Márquez (2020: 273). 
domiciliario. En especial, se hizo común encontrar soluciones aplicando tácitamente la analogía con respecto a las previstas en los reglamentos para permitir el voto por delegación y el voto telemático ${ }^{24}$.

Con el tiempo y la evolución de la crisis sanitaria, algunas de dichas soluciones se han consolidado a impulsos de prácticas cuya reiteración ha permitido, de hecho, orillar la discusión sobre su fundamentación jurídica. Incluso, las soluciones examinadas han recibido acogida en algunas reformas reglamentarias ${ }^{25}$. Con todo, para evaluar las decisiones adoptadas en las semanas concretas de la fase más aguda de la pandemia debe tenerse en cuenta la incertidumbre propia de aquel momento, en el que hubo que articular rápidamente instrumentos que permitieran un cierto grado de continuidad de la actividad parlamentaria sin que, por entonces, hubiera precedentes de una situación semejante.

24 García-Escudero Márquez (2020: 24) admite que la habilitación en el Congreso de los Diputados y el Senado del formato reducido de asistencia y la ampliación de los supuestos de autorización del voto telemático mediante acuerdo de Mesa se han llevado a cabo por analogía con los supuestos de voto telemático permitidos en los respectivos reglamentos.

25 De hecho, las reformas de reglamentos parlamentarios aprobadas en el curso de la pandemia se han producido después de la fase más aguda, ya en el proceso de recuperación de la actividad parlamentaria ordinaria. Estas reformas han ido dirigidas a ampliar los supuestos de voto por delegación o telemático, o bien a prever el voto delegado o telemático en comisiones. En este sentido, la reforma del Reglamento del Parlamento de Andalucía de 6 de mayo de 2020, que añade un art. 90 bis que permite la delegación de voto en las comisiones; la reforma del art. 111.2 del Reglamento de la Junta General de Asturias de 20 de mayo de 2020, que extiende los supuestos en que se permite la emisión del voto telemáticamente, y la aprobada el 15 de julio de 2020, que permite la comparecencia mediante videoconferencia en las comisiones de expertos e interesados; la reforma del Reglamento del Parlamento de Canarias de 20 de mayo de 2020, que regula la participación telemática en supuestos extraordinarios; la reforma del art. 84 del Reglamento del Parlamento de Galicia, de 6 de octubre de 2020, que permite aplicar el voto delegado, sistemas de videoconferencia o cualquier otro sistema técnico y viable para garantizar la participación en las sesiones y los debates y el ejercicio del derecho de voto en situaciones declaradas de riesgo grave para la salud, y la reforma del art. 122 del Reglamento del Parlamento de las Islas Baleares, de 22 de diciembre de 2020, que regula la participación virtual y el voto telemático en circunstancias de ámbito general y carácter grave y extraordinario. 


\section{LA CONVOCATORIA DE LA DIPUTACIÓN PERMANENTE Y EL ARTÍCULO 116.5 DE LA CONSTITUCIÓN}

Bajo nuestro punto de vista, resulta indudable que el funcionamiento de los Parlamentos de las comunidades autónomas no puede interrumpirse durante la vigencia de un estado de alarma. La cuestión reside, más bien, en determinar cuál es la norma de la que se deduce dicha conclusión y cuál es el grado de actividad parlamentaria que debe mantenerse necesariamente.

Con respecto a la primera cuestión, la duda se centra en si resulta aplicable la norma del art. 116.5 de la Constitución según la cual el funcionamiento del Congreso y "de los demás poderes constitucionales del Estado» no podrá interrumpirse durante la vigencia de los estados de alarma, excepción y sitio.

En nuestra opinión, para interpretar correctamente dicho inciso es necesario contextualizarlo. El art. 116 tiene como fin último establecer unos contrapesos a la actividad del Gobierno relativa a la declaración y prórroga de los estados de alarma, excepción y sitio y a la ejecución por aquel de las medidas que se acuerden para reconducir la situación excepcional. Con respecto a la declaración y la prórroga de dichos estados, el contrapeso es el Congreso de los Diputados, que está llamado a autorizar la prórroga del estado de alarma y la declaración y prórroga del estado de excepción, así como a declarar el estado de sitio. En relación con la ejecución de las medidas adoptadas en el curso de dichos estados excepcionales, se prevé la continuidad de los controles políticos y jurídicos ordinarios y, a tal fin, se establecen la convocatoria de las Cámaras si no estuvieran reunidas, la prohibición de interrupción del funcionamiento de las Cámaras y de los demás poderes constitucionales del Estado y el mantenimiento del principio de responsabilidad del Gobierno y sus agentes.

En fin, el art. 116.5 va dirigido, ante todo, a mantener el funcionamiento de las Cortes ${ }^{26}$ y de los demás órganos constitucionales del Estado, a los que corresponde el control político y jurídico de la actuación del Gobierno durante los estados de alarma, excepción y sitio. Adviértase, por ejemplo, la relevante

26 Adviértase que, mientras en la autorización de la prórroga del estado de alarma y de la declaración y prórroga del estado de excepción, así como en la declaración del estado de sitio, la única Cámara llamada a intervenir es el Congreso de los Diputados, el art. 116.5 prevé la convocatoria de ambas Cámaras, si no estuvieran en período de sesiones, lo cual puede interpretarse como un reconocimiento implícito de la facultad de control político en relación con la actividad del Gobierno que también corresponde al Senado. 
función que en estos contextos de excepción pueden desempeñar los órganos judiciales y el Tribunal Constitucional, dado lo previsto en el apdo. sexto del art. 115 de la Constitución.

Además, se puede afirmar que el art. 116.5 prohíbe al Gobierno aprovechar la declaración de alguno de los estados de excepción para interrumpir el funcionamiento de los poderes del Estado, algo que no está de más para evitar la tentación de un uso desproporcionado de la facultad que tiene el Gobierno de limitar derechos tales como el de reunión y el de libre circulación con el fin de clausurar el Congreso u otras instituciones estatales. Así, el inciso destacado supone la garantía de la continuidad del orden constitucional durante la vigencia de los estados de alarma, excepción y sitio frente a la acción del Gobierno.

Con respecto a los Parlamentos de las comunidades autónomas, dejando aparte la prohibición de interrumpir su funcionamiento por parte del Gobierno, que va también ínsita en el propio principio de autogobierno, pensamos, sin embargo, que el elemento que garantiza el desarrollo de sus funciones es el principio general de continuidad de la institución parlamentaria, que se deduce de la previsión de la Diputación Permanente como solución de continuidad para los períodos de suspensión de la actividad parlamentaria. No obstante, la conclusión es la misma, es decir, la necesaria preservación del funcionamiento de dichos Parlamentos durante la vigencia de los estados excepcionales.

Sentado lo anterior, la discusión se encamina a determinar el grado de actividad que deben mantener los Parlamentos de las comunidades autónomas. En nuestra opinión, dado que el art. 116.2 versa solamente sobre las Cortes, con lógico hincapié en el Congreso de los Diputados, ello permite $a$ sensu contrario disponer de mayor margen de actuación a los Parlamentos de las comunidades autónomas para, en ejercicio del principio de autonomía parlamentaria, adaptar su organización y funcionamiento durante los estados de excepción, tras ponderar la especificidad de cada situación. En conclusión, la habilitación de la convocatoria de la Diputación Permanente cumplió durante la fase más aguda de la pandemia las exigencias derivadas del principio de continuidad de la institución parlamentaria, pero igualmente cumpliría la regla del segundo párrafo del art. 116.5 de la Constitución, de estimarse aplicable aquella. No puede olvidarse que el sentido de esta solución era, precisamente, abrir la puerta a continuar la actividad parlamentaria, en un contexto en el que la otra alternativa más factible parecía ser la suspensión absoluta de dicha actividad.

Por otra parte, no puede perderse de vista que las alteraciones provocadas en la actividad parlamentaria ordinaria a partir de marzo de 2020 no han 
tenido como origen la declaración del estado de alarma ${ }^{27}$, sino la propia naturaleza de la situación que provocó la instauración de dicho estado, es decir, la existencia de una emergencia sanitaria a causa de una pandemia provocada por un virus altamente contagioso, para el que no se conocía remedio y que podía poner en peligro la integridad y la vida de las personas expuestas a su efecto. Ello se advierte claramente en la reacción de los Parlamentos frente a la pandemia, que ha seguido unos ritmos diferentes a los que marca la declaración del estado de alarma. La suspensión o la limitación de las actividades se acordaron en algunos Parlamentos en la semana anterior, y, aunque lógicamente el curso de la actividad parlamentaria se ha visto influido por las medidas propias del estado de alarma, la llamada "desescalada» ha sido administrada por los Parlamentos conforme a los acuerdos adoptados por sus órganos de gobierno de forma autónoma ${ }^{28}$.

27 Acordada, como es conocido, mediante el Real Decreto 463/2020, de 14 de marzo, por el que se declara el estado de alarma para la gestión de la situación de crisis sanitaria ocasionada por la COVID-19, y prorrogada mediante los reales decretos 476/2020, de 27 de marzo, 487/2020, de 10 de abril, 492/2020, de 24 de abril, $514 / 2020$, de 8 de mayo, y 555/2020, de 5 de junio. En conjunto, el estado de alarma se extendió desde el 14 de marzo de 2020 hasta las 00:00 horas del 21 de junio del mismo año.

No podemos detallar los acuerdos y normas aprobados por cada uno de los Parlamentos de comunidades autónomas. Por poner un ejemplo que ilustra la tendencia general, la Mesa del Parlamento de Andalucía acordó el 12 de marzo de 2020 suspender la actividad parlamentaria del resto de la semana (llegaron a celebrarse las comisiones que tenían fijada sesión para la mañana de ese día), para lo que fue determinante el hecho de que los diputados del Grupo Parlamentario Vox en Andalucía decidieran aislarse voluntariamente en sus domicilios, al haber asistido al acto de dicho partido en Madrid el 8 de marzo, y tras conocerse el positivo en covid-19 del secretario general del citado partido. El inicio de la desescalada se dio en el Parlamento de Andalucía mediante la Resolución del 29 de abril, que dejaba sin efecto la Resolución de 16 de marzo, que habilitó la convocatoria de la Diputación Permanente y el acuerdo de la Mesa de la misma fecha, que decidió volver a convocar al Pleno y a las comisiones para tramitar determinadas iniciativas relacionadas con la covid-19 y con presencia reducida de diputados, a lo que siguieron otros acuerdos en los meses de mayo y junio que permitieron recuperar progresivamente la normalidad de la actividad parlamentaria, salvo la presencia reducida de diputados, que sigue manteniéndose cuando se termina de redactar el presente trabajo. En general, en los Parlamentos de comunidades autónomas las medidas comenzaron a aplicarse en los días previos a la declaración del estado de alarma y la vuelta progresiva a la normalidad comenzó en la segunda quincena del mes de abril. 
Ciertamente, la mayoría de los acuerdos y resoluciones de los Parlamentos tendieron, una vez declarado el estado de alarma, a referenciar la duración de las medidas adoptadas a la de aquel, pero este es un dato del que no se pueden sacar conclusiones determinantes, ya que se explica porque en un principio se podía pensar que el estado de alarma durara menos tiempo, por la recíproca identificación entre crisis sanitaria y estado de alarma y porque dicha referencia, normalmente, iba acompañada de una cláusula que permitía adaptar las medidas conforme a la evolución de las circunstancia ${ }^{29}$.

\section{LAS FUNCIONES ASUMIDAS POR LAS DIPUTACIONES PERMANENTES EN EL MARCO DE LA CRISIS SANITARIA}

La doctrina ha afirmado de forma unánime que la Diputación Permanente es un órgano de continuidad de la institución parlamentaria, pero que no sustituye al Pleno, sino que se subroga en algunas de sus funciones para garantizarlas mientras no esté reunido (Manzella, 1980: 496; Caamaño Domínguez, 1991: 294), estando normalmente caracterizadas sus funciones por ceñirse al plano administrativo o por su carácter político y extraordinario (Pérez Serrano, 1984: 175). En la Constitución, sus atribuciones quedan limitadas a lo dispuesto en el art. 78.2.

Sin embargo, se ha acuñado un esquema diferente de funcionamiento de la Diputación Permanente durante la fase más aguda de la emergencia sanitaria de la covid-19. Las Mesas y Juntas de Portavoces de las Cámaras siguieron funcionando, si bien por vía telemática, como órganos de admisión de iniciativas y de fijación del orden del día de las sesiones de la Diputación Permanente. Por su parte, las Diputaciones Permanentes se han convertido en los órganos donde se han sustanciado dichas iniciativas, conforme al orden del día previamente acordado, integrado, en el supuesto habitual, por comparecencias de los miembros del Consejo de Gobierno en relación con las medidas aplicadas con respecto a la covid-19 y por la convalidación o derogación de decretos leyes.

Dando por sentado el principio de autonomía parlamentaria en la faceta atinente a la organización de la Cámara, la cuestión reside en determinar si

29 Por ejemplo, el acuerdo de la Mesa del Parlamento de Andalucía de 16 de marzo de 2020, sobre las medidas adoptadas durante la vigencia del estado de alarma ocasionado por la COVID-19, previó «adaptar la actividad parlamentaria de la Cámara, con suspensión de las sesiones previstas durante el tiempo que dure el estado de alarma, sin perjuicio de la posibilidad de modificar las medidas adoptadas en este acuerdo si las circunstancias así lo aconsejan». 
este modo de funcionar de una Diputación Permanente puede encuadrarse dentro de la función de velar por los poderes de la Cámara cuando no esté reunida, generalmente reconocida en todos los estatutos de autonomía o reglamentos parlamentarios siguiendo el modelo del art. 78.2 de la Constitución ${ }^{30}$. Como era de esperar, dada la imprecisión de esta cláusula, la doctrina ha mantenido diversas interpretaciones sobre su alcance (Santaolalla López, 2013: 223).

Aizpuru Segura (2012: 484) resume el sentir comúnmente admitido al afirmar «que no implica ejercer los poderes sino garantizarlos, defenderlos». En el mismo sentido, Santaolalla López (2013: 224) esgrime que dicha función parece estar pensada con un carácter simbólico y no permite que dicho órgano se subrogue en las funciones típicas de las Cámaras. Ahora bien, la doctrina, simultáneamente, ha admitido la posibilidad de hacer un uso más amplio de dicha norma. Para empezar, algunos autores admiten el ejercicio de determinadas funciones adjetivas o secundarias que resulten inaplazables (Lavilla Rubira, 1998: 698), la adopción de decisiones de particular gravedad cuando lo exijan las circunstancias (Pérez Dobón, 1984: 34) o, en los períodos entre legislaturas, determinadas funciones en defensa de la posición constitucional de la Cámara y como garantía del equilibrio de poderes (Guillén López, 2002: 192-199). Por otra parte, los reglamentos de los Parlamentos de las comunidades autónomas ańaden, en ocasiones, a las Diputaciones Permanentes funciones que exceden del esquema al uso (Visiedo Mazón, 2016: $223-224)^{31}$.

30 Hay excepciones. El Reglamento de la Junta General de Asturias no contiene la citada regla, pero en su art. 80.b) establece que la Diputación Permanente, «terminado el mandato del Parlamento, podrá ejercer, en casos de urgencia o extraordinaria necesidad, las competencias de la Cámara que resulten adecuadas». El art. 68 del Reglamento de la Asamblea Regional de Murcia limita la función de velar por los poderes de la Asamblea a cuando la Cámara haya sido disuelta o se haya agotado la legislatura. El art. 68.1 del Reglamento del Parlamento de Navarra establece que en los casos de expiración del mandato la Comisión Permanente "podrá ejercer, por razones de extraordinaria y urgente necesidad, todas las funciones de la Cámara».

31 Como funciones singulares, el art. 52.1.d) del Reglamento del Parlamento de La Rioja le atribuye la función de resolver en lectura única sobre mociones o proposiciones no de ley y asuntos urgentes; el art. 82.d) del Reglamento de la Asamblea de Madrid y el art. 52.4 del Parlamento de La Rioja les permiten efectuar las elecciones, designaciones y nombramientos de personas que correspondan a la Cámara por razones de urgencia y necesidad; el art. 75 del Reglamento del Parlamento de Cataluña le permite sustanciar comparecencias del Gobierno y tramitar propuestas de resolución. En algunos casos se recoge la función de autorizar presupuestos 
Finalmente, algunos autores admiten, a partir de la función de velar por los poderes de la Cámara, que «nada impide que la Diputación Permanente, si la urgencia lo requiere, pueda hacer uso de cualquier instrumento parlamentario en casos singulares que así lo requieran» (Visiedo Mazón, 2016: 223), o en situaciones excepcionales (Recoder y García-Escudero, 2010: 1318) o inaplazables (Santaolalla López, 2013: 225) ${ }^{32}$. Entre estos, se ha señalado especialmente la celebración de sesiones informativas en la Diputación Permanente entre períodos de sesiones (Aizpuru Segura, 2012: 485), o bien en los períodos entre legislaturas (Santaolalla López, 2013: 225), que cuenta con algunos precedentes en el Congreso de los Diputados y en Parlamentos de las comunidades autónomas ${ }^{33}$.

El límite, como advierte Santaolalla López (2013: 224), habrían de ser aquellas funciones de las Cámaras que, por su naturaleza, deberían quedar reservadas al Pleno o, en su caso, a las comisiones, como son, a nuestro juicio, la legislativa, presupuestaria, de investidura y de elección de determinados cargos, salvo eventuales excepciones en los reglamentos parlamentarios ${ }^{34}$.

extraordinarios, además de suplementos de crédito y créditos extraordinarios, a petición del Gobierno, por razón de urgencia y de necesidad justificada (arts. 55.1.5. ${ }^{\circ}$ del Reglamento del Parlamento de Galicia, 99.3.b del Reglamento de las Cortes de Aragón, $70.5 .^{\circ}$ del Reglamento del Parlamento de Canarias). Véase también la nota anterior.

32 Prescindimos de tratar sobre la distinción de funciones de la Diputación Permanente entre los períodos entre sesiones y los períodos entre legislaturas, que resulta de interés secundario para el concreto objeto del presente artículo.

33 Comparecencia del ministro de Defensa para informar sobre los hechos que han dado lugar a la detención de tres jefes militares, el 11 de octubre de 1982 (Diario de Sesiones del Congreso de los Diputados, Diputación Permanente, n. ${ }^{\circ} 2$, de 11 de octubre); información del señor presidente del Gobierno sobre la remodelación del Gabinete, llevada a cabo recientemente, el 11 de julio de 1985 (Diario de Sesiones del Congreso de los Diputados, Diputación Permanente, n. ${ }^{\circ}$ 1, de 11 de julio). Existen también precedentes en los Parlamentos autonómicos. Así, por ejemplo, en el Parlamento de Andalucía, la comparecencia del Consejo de Gobierno ante la Diputación Permanente el 27 de febrero de 2015, para informar sobre los últimos acontecimientos que afectan a la Administración autonómica respecto de los fondos públicos concedidos para la realización de cursos de formación para el empleo.

34 La excepción más conocida es la prevista en el art. 151.5 del Reglamento del Congreso de los Diputados, que ha sido trasladada a los reglamentos de algunos Parlamentos de comunidades autónomas (arts. 158.5 del Reglamento del Parlamento de Cataluńa, 148.5 del Reglamento del Parlamento de las Islas Baleares, 212.3 del Reglamento de las Cortes de Aragón, 141.3.4. ${ }^{\circ}$ del Reglamento de las Cortes Valencianas, 
Por nuestra parte, estimamos que la función de velar por los poderes de la Cámara es lo suficientemente genérica como para permitir el ejercicio por la Diputación Permanente de funciones de control y de impulso de la acción del Ejecutivo, siempre que, por concurrir circunstancias excepcionales constitutivas de fuerza mayor, resulte imposible, o plantee graves dificultades, reunir a los órganos que normalmente habrían de tramitarlas, ya sea el Pleno, ya sean las comisiones. En este particular contexto, la función de velar por los poderes de la Cámara sería suficiente, al menos, para dar cobertura a la celebración de comparecencias informativas de los miembros del Ejecutivo ante el Parlamento e, incluso, al debate de iniciativas de impulso de la acción del Gobierno.

Con respecto a la convalidación de decretos leyes, el art. 78.2 de la Constitución sienta un principio general según el cual aquella es una actuación admisible en las Diputaciones Permanentes. Que esta facultad se limite a los lapsos entre legislaturas, o bien se extienda a los períodos entre sesiones, constituye ya una decisión particular que, sentado el principio anterior, queda, en nuestra opinión, a lo que disponga el reglamento del Parlamento de cada comunidad autónoma (SSTC 179/1989, FJ 7, 116/1994, FJ 5, y 84/2015, FJ 4.a). La normativa del Parlamento de Andalucía, del Parlamento de las Islas Baleares y de las Cortes Valencianas permite la convalidación de decretos leyes por la Diputación Permanente tanto en el período entre legislaturas como en el supuesto de "vacaciones parlamentarias», es decir, en todos los casos en que se prevé su actuación (Resolución de la Presidencia del Parlamento de Andalucía, de 5 de junio de 2008, sobre control por el Parlamento de los decretos leyes dictados por el Consejo de Gobierno, art. 148 del Reglamento del Parlamento de las Islas Baleares, que no limita esta función a un determinado período, y art. 61 del Reglamento de las Cortes Valencianas). La relativa al Parlamento de Canarias y a la Asamblea de Extremadura prevé la convalidación en la Diputación Permanente en los supuestos de disolución de la Cámara o expiración de su mandato (art. 160.5 del Reglamento del Parlamento de Canarias y Resolución de la Presidencia de la Asamblea de Extremadura, de 27 de septiembre de 2016, que, con discutible técnica normativa, recoge esta función en su preámbulo).

161.5 del Reglamento del Parlamento de Navarra), y que ha recibido merecida crítica de la doctrina (Jiménez Campo, 1982: 46-54). Para otras excepciones, véanse las notas 31 y 32 . Como es lógico, estas previsiones solamente son admisibles si resultan compatibles con la Constitución y el respectivo estatuto de autonomía, apreciación esta que nos llevaría a un análisis que excusamos en este momento, por exceder del ámbito propio del presente trabajo. 
En nuestra opinión, como dijimos anteriormente, se encuentran elementos suficientes para referenciar a ambas situaciones, por analogía, la actuación de la Diputación Permanente en la situación vivida durante la fase más aguda de la pandemia de la covid-19. Por otra parte, la convalidación de los decretos leyes era una actuación urgente y necesaria para evitar su derogación por el transcurso del plazo previsto en los estatutos de autonomía para llevar a cabo esta actuación, tanto más si cabe por cuanto estas normas estaban destinadas a afrontar urgentemente los retos sanitarios, económicos y sociales que generó la pandemia.

\section{CONSIDERACIONES FINALES Y CONCLUSIONES}

Las medidas adoptadas por los Parlamentos, tanto estatal como autonómicos, para adaptar su actividad con el fin de afrontar las dificultades derivadas de la covid-19 deben examinarse dentro de un contexto definido por dos elementos.

En primer lugar, la crisis sanitaria del coronavirus ha supuesto que la salud pública emerja con toda evidencia como bien jurídico apto para ser tomado en consideración por los poderes públicos en la ponderación con derechos fundamentales y otros bienes y valores protegidos por la Constitución. Ya estaba considerado como posible límite a determinados derechos en el Convenio Europeo de Derechos Humanos (arts. 8.2, 9.2, 10.2 y 11.2 y art. 2.3 del Protocolo número 4) y gozaba de reconocimiento y protección en la Constitución (art. 43.2) y en las leyes, tanto estatales (Ley Orgánica 3/1986, de 14 de abril, de Medidas Especiales en Materia de Salud Pública, y Ley 33/2011, de 4 de octubre, General de Salud Pública) como autonómicas, pero los riesgos derivados de la covid-19 han hecho que la protección de la salud pública, abruptamente, haya comenzado a condicionar las actuaciones de los poderes públicos, transversalmente, en varias materias, aun cuando esto conllevara limitaciones a determinados derechos fundamentales (Delgado del Rincón, 2020: 2).

En segundo lugar, es necesario tomar en consideración la gravedad del riesgo sanitario derivado de la covid-19 para la salud, la integridad y la vida de los diputados y del personal que trabaja en las Cámaras, las dificultades a la movilidad de los diputados y de dicho personal derivadas de las medidas adoptadas en el marco del estado de alarma y las recomendaciones de las autoridades sanitarias para limitar drásticamente las reuniones y los desplazamientos, todo ello en un marco de alarma pública especialmente perceptible entre segunda mitad de abril y la primera mitad de mayo de 2020.

En este contexto, resulta comprensible que la crisis sanitaria de la covid-19, en su fase más aguda, provocara un grave trastorno en la actividad 
parlamentaria. Resultaba imposible desarrollar la actividad parlamentaria de manera normal, si se quería proteger la salud de los diputados y el personal de los Parlamentos y evitar otros inconvenientes anejos a la pandemia y a la declaración del estado de alarma. La dificultad se veía agravada, además, por el carácter novedoso de la emergencia, que no estaba prevista en los reglamentos parlamentarios y para cuyo tratamiento los Parlamentos no estaban preparados.

Para preservar, siquiera, un limitado grado de actividad parlamentaria en estas excepcionales circunstancias, los distintos Parlamentos han tenido que articular soluciones novedosas. Estas opciones solamente se pueden comprender desde interpretaciones de los reglamentos de tipo finalista, que se alejan de planteamientos dogmáticos o literales, en aras de encontrar soluciones útiles para mantener la actividad parlamentaria en términos compatibles con la preservación de la salud de los diputados y del personal al servicio del Parlamento, con la finalidad de evitar las trabas a los desplazamientos derivadas de las medidas de confinamiento y con la necesidad de dar ejemplo a la ciudadanía de cumplimiento de las recomendaciones de las autoridades en materia sanitaria.

La convocatoria de la Diputación Permanente durante la fase más aguda de la crisis sanitaria de la covid-19 en algunos Parlamentos debe encuadrarse en dicho marco. Se trató de una solución excepcional para una situación excepcional y permitió en algunos Parlamentos hacer compatible la atención a las exigencias derivadas de la protección de la salud pública con el mantenimiento de la actividad parlamentaria, al menos, en la medida indispensable para controlar la actuación de los correspondientes Ejecutivos durante la fase más aguda de la pandemia y convalidar los decretos leyes.

Esta solución puede fundamentarse desde la evidencia de una laguna normativa, dado que los reglamentos no preveían expresamente este tipo de crisis sanitarias, pero tampoco era razonable pensar que hubiera tras ello una voluntad de dejarlas desatendidas, y es resultado del principio general que impone la continuidad de la institución parlamentaria y del uso de la analogía, que, a nuestro juicio, permite aplicar la convocatoria de la Diputación Permanente, como solución de continuidad prevista para los supuestos de cese de la actividad parlamentaria por disposición normativa (suspensión de la actividad entre períodos de sesiones y disolución de las Cámaras por expiración de su mandato o convocatoria anticipada de elecciones), a los supuestos sobrevenidos de cese de la misma actividad por circunstancias de fuerza mayor, en virtud de las semejanzas entre uno y otro supuesto que hemos examinado en el presente trabajo.

El carácter extraordinario de esta solución lleva en sí su carácter transitorio. Lógicamente, la habilitación de la Diputación Permanente se mantuvo en determinados Parlamentos hasta que se estimó posible aplicar opciones más aproximadas a la normalidad de la actividad parlamentaria. Este carácter 
excepcional y transitorio, por cierto, debe predicarse también de las demás soluciones que se vienen aplicando en este marco de pandemia. Opciones como la generalización del voto delegado o telemático o la presencia reducida de diputados no pueden consolidarse como normales y solamente tienen sentido mientras permanezca el riesgo sanitario asociado a la pandemia.

Por otra parte, la Diputación Permanente ha quedado enmarcada en el período examinado en un esquema organizativo original, en el que simultáneamente se reunían la Mesa de la Cámara y la Junta de Portavoces, y ha asumido funciones diferentes de las habituales. Como hemos visto, el principio de autonomía parlamentaria, en su faceta organizativa, y una interpretación flexible de la competencia de velar por las funciones de la Cámara permiten dar fundamento a estas novedades.

La convocatoria de la Diputación Permanente y las demás soluciones adoptadas por los Parlamentos para mantener un cierto grado de actividad deben valorarse como instrumentos de afirmación de la presencia del Parlamento en el control de la actividad de los respectivos Ejecutivos y, en general, en el espacio público, en tiempos de especial dificultad para la actividad parlamentaria, y en una situación inicial en la que no había precedentes de soluciones alternativas.

Ahora bien, lo anterior no esconde que el diseño y la aplicación de estas soluciones se han llevado a cabo a través de resoluciones de la presidencia y de acuerdos de Mesa. En el marco de una laguna normativa, además, se ensanchaba el ámbito para el acuerdo entre los actores políticos en torno a la opción concreta que hubiera de adoptarse en cada Parlamento. De hecho, no es difícil advertir el juego de contrapesos entre mayoría y minoría en la opción de suspender la actividad parlamentaria y, al mismo tiempo, habilitar la convocatoria de la Diputación Permanente para asegurar el control del Ejecutivo, de forma que ambas decisiones se condicionaran recíprocamente.

Sin embargo, esta realidad ha terminado afectando en algunos Parlamentos a la estabilidad de los acuerdos, a causa de la dinámica inherente a la confrontación política. Por ello, resulta conveniente que, en aras de una mayor seguridad jurídica, los Parlamentos incorporen a sus reglamentos la solución para los supuestos en los que situaciones de fuerza mayor ocasionen perturbaciones graves a su actividad.

\section{BIBLIOGRAFÍA}

Aizpuru Segura, A. (2012). Artículo 57. En R. Ripollés Serrano (coord.). Comentarios al Reglamento del Congreso de los Diputados (pp. 480-490). Madrid: Congreso de los Diputados. 
Alonso de Antonio, A. L. (1986). La diputación permanente en el sistema parlamentario español. Revista de las Cortes Generales, 8, 133-187. Disponible en: https://doi. org/10.33426/rcg/1986/8/443.

Astarloa Huarte-Mendicoa, I. (2016). Estudio preliminar: evolución del Derecho parlamentario autonómico y sus fuentes. En S. Iglesias Machado y R. Marañón Gómez (coords.). Manual de Derecho parlamentario autonómico (pp. 17-54). Madrid: Dykinson.

Caamaño Domínguez, F. (1991). El mandato parlamentario. Madrid: Congreso de los Diputados.

Delgado del Rincón, L. E. (2020). Algunas consideraciones sobre el derecho a la protección de la salud y el bien jurídico de la salud colectiva en tiempos de pandemia. En P. Biglino Campos y J. F. Durán Alba (dirs.). Los efectos horizontales de la COVID-19 sobre el sistema constitucional: estudios sobre la primera oleada. Zaragoza: Fundación Giménez Abad. Disponible en: https://doi.org/10.47919/FMGA.OC20.0017.

Ezquiaga Ganuzas, F. J. y Saiz Arnaiz, A. (1987). Lagunas reglamentarias y función supletoria del Presidente del Congreso de los Diputados. Revista Vasca de Administración Pública, 17, 7-28.

Fernández Gutiérrez, M. (2020). La Junta General del Principado de Asturias bajo la pandemia ocasionada por la COVID-19. En J. Tudela Aranda (dir.). El Parlamento ante la COVID-19 (pp. 53-65). Zaragoza: Fundación Giménez Abad de Estudios Parlamentarios y del Estado Autonómico.

García-Escudero Márquez, P. (2020). La ductilidad del derecho parlamentario en tiempos de crisis: actividad y funcionamiento de los Parlamentos durante el estado de alarma por COVID-19. Teoria y Realidad Constitucional, 46, 271-308. Disponible en: https://doi. org/10.5944/trc.46.2020.29113.

González Ayala, M. D. (1987). La continuidad de las Cámaras parlamentarias. Las distintas soluciones constitucionales. Anuario de la Facultad de Derecho. Universidad de Extremadura, 5, 73-86.

Guerrero Vázquez, P. (2020). El sistema parlamentario británico ante la COVID-19. En J. Tudela Aranda (dir.). El Parlamento ante la COVID-19 (pp. 200-215). Zaragoza: Fundación Giménez Abad de Estudios Parlamentarios y del Estado Autonómico.

Guillén López, E. (2002). La continuidad parlamentaria: las Diputaciones Permanentes. Madrid: Civitas.

Iturbe Mach, A. (2020). El Parlamento Vasco en tiempos virulentos. Una crónica desapasionada y un colofón. En J. Tudela Aranda (dir.). El Parlamento ante la COVID-19 (pp. 94-103). Zaragoza: Fundación Giménez Abad de Estudios Parlamentarios y del Estado Autonómico.

Jiménez Campo, J. (1982). La Diputación Permanente y el control sobre el decreto-ley. Revista de Derecho Político, 15, 35-55. Disponible en: https://doi.org/10.5944/ rdp.15.1982.8180.

Kölling, M. (2020). El Bundestag y el Bundesrat alemán en tiempos de COVID-19. En J. Tudela Aranda (dir.). El Parlamento ante la COVID-19 (pp. 189-199). Zaragoza: Fundación Giménez Abad de Estudios Parlamentarios y del Estado Autonómico.

Lavilla Rubira, J. J. (1998). Artículo 78. Las Diputaciones Permanentes del Congreso de los Diputados y del Senado. En O. Alzaga Villaamil (dir.). Comentarios a la Constitución española de 1978 (pp. 686-762). Edersa: Madrid. 
Manzella, A. (1980). Las Cortes en el sistema constitucional español. En I. Predieri y E. García de Enterría (dirs.). La Constitución española de 1978 (pp. 477-524). Madrid: Civitas.

Morales Arroyo, J. M. (1996). Un avance en el control jurisprudencial de las resoluciones parlamentarias. Revista Española de Derecho Constitucional, 56, 257-281.

Nieto Jiménez, J. C. (2020). Parlamento y crisis sanitaria: análisis constitucional de la Resolución de la Presidencia del Parlamento de Andalucía «sobre habilitación de la convocatoria de la Diputación Permanente en una situación de declaración de estado de alarma». Cuadernos Manuel Giménez Abad, 20, 253-270. Disponible en: https://doi. org/10.47919/FMGA.CM20.0041.

Pardo Falcón, F. J. (2005). ¿Lagunas en el Reglamento Parlamentario? A propósito de las SSTC 226 y 227/2004, de 29 de noviembre, relativas a la disolución anticipada de la Comisión de investigación sobre la catástrofe del Prestige en el Parlamento de Galicia. Repertorio Aranzadi del Tribunal Constitucional, 1, 13-30.

Pérez Dobón, J. J. (1984). Les activités parlementaires après la dissolution de la Chambre: la Députation Permanente espagnole. Informationes Constitutionnelles et Parlementaires, 137.

Pérez Serrano, N. (1984). La Diputación Permanente de Cortes en nuestro Derecho constitucional histórico. En Escritos de Derecho Politico. Tomo I. Madrid: Instituto de Estudios de Administración Local.

Recoder, E. y García-Escudero, P. (2010). Artículo 78. En F. Garrido Falla (coord.). Comentarios a la Constitución (pp. 1310-1318). Madrid: Civitas.

Ridao Martín, J. (2020). Virtualizando el Parlamento (hasta donde se puede). El régimen de contingencia del Parlamento de Cataluña durante la crisis de la COVID-19 y las reformas tecnológicas y reglamentarias operadas para regular la actividad no presencial en el futuro. En J. Tudela Aranda (dir.). El Parlamento ante la COVID-19 (pp. 76-93). Zaragoza: Fundación Giménez Abad de Estudios Parlamentarios y del Estado Autonómico.

Saiz Arnaiz, A. (1988). El carácter obligatorio de la pertenencia a un grupo parlamentario: el Grupo Mixto y las Agrupaciones en el Congreso de los Diputados. Revista de las Cortes Generales, 13, 90-136. Disponible en: https://doi.org/10.33426/rcg/1988/13/327.

Santaolalla López, F. (2013). Derecho parlamentario español. Dykinson: Madrid.

Sarmiento Méndez, X. A. (2020). La reacción del Parlamento de Galicia ante la crisis sanitaria. ¿Puede la Diputación Permanente ejercer «otras funciones» en una Cámara disuelta? En J. Tudela Aranda (dir.). El Parlamento ante la COVID-19 (pp. 104-114). Zaragoza: Fundación Giménez Abad de Estudios Parlamentarios y del Estado Autonómico.

Tudela Aranda, J. (dir.) (2020). El Parlamento ante la COVID-19. Zaragoza: Fundación Giménez Abad de Estudios Parlamentarios y del Estado Autonómico.

Visiedo Mazón, F. J. (2016). Órganos funcionales, o de trabajo, de los parlamentos. En S. Iglesias Machado y R. Marańón Gómez (coords.). Manual de derecho parlamentario autonómico (pp. 195-224). Madrid: Dykinson. 